\title{
Analysis on Online Learning Environment Construction
}

\author{
Xu Man \\ Northeast Petroleum University, School of Computer and Information Technology, Daqing, Heilongjiang163000
}

\begin{abstract}
Online learning mode is a kind of subversive public class innovation mode. It has been paid attention by the famous universities abroad increasingly since 2012. Since its launch, it has been given attention and praise highly by the educators worldwide. Using the Internet for online learning can promote the transformation of teaching thought, improve teaching means, and improve the teaching quality. Based on the Web2.0 and virtual community we analyze the online learning environment construction.
\end{abstract}

Key Words: Web2.0, informal learning, virtual learning community

The concept of online learning has been hyped for more than ten years. However, online learning has no system and its content is mediocre and obscure. The content of online learning which is patched up from online reading, written question and answer, and the lecture video with low-cost production hadn't get many constant attentions. The conflicts, such as the continuous development of Internet technology, the rise in education cost and the compression of government investment, prompt us to reconsider and integrate the education resources.

Online learning abroad has developed rapidly. In order to avoid being left behind in the education competition in the future, domestic colleges and universities also have carried out the plans and launched their own online learning platforms, and the online learning will become novel and influential learning mode.

\section{The Typical Application of Web2.0}

\subsection{Blog}

Blog's English full name is Weblog, later it is abbreviated for Blog. Blog is the most core application of Web2.0. And it dominates the market in the world's largest internet population and it is most widely used among all the applications of Web2.0. It is a kind of Internet publishing and communication form, which is listed in time sequence and is used to express personal thought and content. It has very strong personalized features. Users can use Blog to release the logs, pictures, comments, and others very easily, and they also can share and reproduce the information published by other Internet users. It is a space used by the users to reflect, create and show themselves. At the same time, it is also a platform used for communicating, obtaining and sharing the resources among the users. It has very important significance to the sharing and mining of tacit knowledge.

\subsection{RSS}

RSS was born in 1997, and its English full name is Really Simple Syndication. RSS takes Xml as the technology base to complete the automatic transmissions of information among the Internet sites. It is a kind of information polymerization technology, which is used to share the information contents among the Internet sites. It gives the autonomy of using information to the users. With the help of the RSS function, the users can directly read the contents of multiple sites without the login to the sites. RSS has two characteristics: First, it can search the subscription information within the Internet automatically. Second, the transmitted content is the classified index information. With the help of the RSS function, the users can use the online or offline RSS reader to browse the information summary on the website. The users can get the content of the website without logging in each site. The frequently-used RSS readers are shown as follows, MyMSN, Blog network RSS 
expo, Sina and tong, POTU, etc.

\subsection{Tag}

The Chinese translation of Tag is the label, and it is also called "folksonomy". It is a kind of way, which uses the keywords with free choice to classify the contents of website information. It is a flexible classified way, and it uses that kind of multiple, overlapping and associative way which is like the brain thinking, to retrieve. It is also a kind of free and orderly classification technique. The users can add more than one Tags for each log. The system will use RSS aggregation function to present the log content with the same Tag labeling to the users so as to establish the contacts and communications among the users. Therefore, Tag makes the valuable information content be presented to the users with more details. And at the same time, it also enhances the correlations among the logs and the interactions among the users.

\subsection{Wiki}

The word Wiki, which derives from the "weekeeweekee" in Hawaiian, has the original meaning, "hurry up, hurry up". It is usually translated as "Wiki”. Wiki is a kind of writing tool which supports many people to collaborate. The users can edit jointly, save the edited content, and constantly enrich and improve the content. It is a kind of hypertext system. It provides the auxiliary tool of collaborative writing, and it can provide the necessary support for the users' collaborative writing. The users can attend the activities to create and share knowledge together. Wiki site can be maintained by many people. Everyone can create, browse, change the text, give their views, and discuss and extend the common themes. Its purpose is to realize the knowledge sharing, communication, accumulation, spread and recreation.

\section{Virtual Learning Community------- an Important Way of Informal Learning \\ 2.1 Abound Informal Learning}

As the pace of life continues to increase, people need to adapt to the development of the society, and keep up with the pace of The Times, so it requires people to have fast learning ability, and quickly obtain the knowledge. In social life the channels which we can obtain the knowledge mainly are via the form of informal learning. Studies show that $80 \%$ or even greater proportion of the knowledge obtained in people's lives is from the informal learning. Therefore, there is a lot of informal learning. It can happen anywhere and anytime. It is more important that the knowledge obtained through the informal learning is more valuable for people and the effect obtained through the learning is more apparent.

\subsection{Virtual Learning Community------- an Important Way of Informal Learning}

The diversification of network information and the network of lifestyle make people's life, work and study be more convenient. Thus, these provide people with more efficient and convenient way of informal learning, and more and more people use the Internet for working as well as socializing and learning. However, with the surge of network information, it makes a lot of information garbage appear online. People need to spend more time and energy in the process of screening information. It increases the burden of learning, and it runs contrary to the informal learning which we obtain the knowledge quickly. However, in virtual learning community, people can participate in the learning to form a specific network social group according to their own needs and willingness. In virtual learning community, people can communicate, discuss, interact and collaborate mutually, and share each other's viewpoints, learning experience, taste and others to achieve the goal of mutual learning, and meet the needs of their own learning. This is exactly the embodiment of the informal learning. People learn in social intercourse activity and learn in the communication. Learning is a kind of incidental activity with social interaction. In the virtual learning community, its members have certain professionalism so as to make the resources in the 
community also have professional directivity. The information in it is more targeted, and is more convenient for the learners to screen the information so as to meet the needs of fast learning. Thus, virtual learning community is an important way of informal learning.

\section{Web2.0 injects new vitality to the virtual learning community}

\subsection{The core concept of Web2.0 is consistent with the core elements of virtual learning} community

Sharing, equality, freedom and openness, emphasizing the participation of ordinary users and active contribution, and having obvious self-organizing and grassroots are the core concept of Web2.0. While the voluntary and active participation of the users with the interests on something is also one of the core elements of virtual learning community. In the virtual learning community, everyone is equal, and we can find people with the same interests and hobbies to communicate and learn, and share each other's experience. This kind of learning can be done at any time. It is a kind of informal learning, and it is a free and flexible learning.

Thus, the core concept of Web2.0 is consistent with the core elements of virtual learning community. It provides the possibility of organically integrating all kinds of technical services of Web2.0 in the virtual learning community to better promote the occurrence of informal learning.

\subsection{Web2.0 provides a new technical support for virtual learning community construction}

The typical applications of Web2.0 have different characteristics. If we can integrate and apply in virtual learning community, it will be better to promote learners' informal learning. Making use of Blog learners can build their own individuality spaces to record their own thoughts. It is advantageous to the re-reflection of the knowledge. Making use of Blog learners also can publish the knowledge which they are interested in and link to some other excellent bloggers' websites so as to learn the recent dynamics of other people and obtain knowledge from others. At the same time, the Blog is also a platform of communicating and sharing with others. Making use of RSS, learners can subscribe for the news and blogs which the learners are interested in, and the websites, news, and others which the learners focus on, and obtain the latest information in time, and eliminate the interference of irrelevant information so as to save a lot of time, improve the learning efficiency and speed, and fully embody the subject status of the learners. Making use of the Tag label, we can mark the resources and contents created by the learners. It can reflect the points of interests which are focused on by different learners in a certain period to a certain extent so as to help us find the people with the same interests. Making use of the micro blogs, learners can have the brief conversations anytime and anywhere with other users about certain question which they are interested in, and publish the related resources to realize the mobile learning. Making use of website extracts, learners can add the websites which they are interested in to their own online bookmarks anytime and anywhere. At the same time, learners can use one or more keywords to manage the website content (Tag) rather than classified identification and their own organized bookmarks, and they can share website contents collected by them with other users. Making use of SNS, Learners can establish and continuously expand their own circles of friends to realize the push of excellent resources and the sharing of resources.

\section{Analysis on Online Learning Framework}

In the process of designing the remote operations education training service platform, we fully consider the learners' characteristics and the actual working environment, and take the learners as the center to design the teaching activities, and give consideration to learning environment, learning cooperation, learning methods, learning resources and other learning factors. We pay attention to divide them in the platform integration architecture according to the logic levels and fully consider the factors which are advantageous to learners' characteristics and learning 
environment.

\subsection{The Definition of Training and Learning Content}

In the process of carrying on whole teaching design in the remote operations education training service platform we should take the learners as the center. In the process of analyzing the specified teaching goal and considering the learning content we should concern this subject of the learners. In the teaching design concept of this platform we should centre on self-guide rather than use the force-feeding education like the traditional training. Teaching goals are planned by the teaching designers. The teaching goal of this platform should be originated from the learners. Secondly, the design of the teaching goal should have the controllability, and can undertake reasonable adjustment, and should respect the original inherent logicality of the teaching subject. Next, we should pay attention to the situation of learning resources in the process of learning, consider the integrity of the learning resources in the process of learning, and emphasize the real and availability of learning resources. Learners can learn and review the knowledge again in the process of completing the actual work task.

\subsection{Analysis on the Remote Training Mode of Individuality Self-guide}

(1) In the remote training mode of individuality self-guide, we make the resources be classified and stratified and collect the information with relevant properties of learners and resources to carry on the tags marks, and make use of resources recommendation algorithm to recommend the needed resources for the learners. Due to the lack of previous learning experience, the beginners only concern the good choice in the process of obtaining the experience, for example, they watch the demo video. They have a certain foundation in the software operation, and learners who have a certain understanding of the business can select to watch the document description. The interactive learning with interaction and mutual consult is also a right learning way for the learners. After the learners complete the learning of resources, they can score the resources and write the comments on resources so as to give the reference opinions for other learners. Generally speaking, the realization of individuality self-guide learning and the abundant education resources are inseparable. We classify the abundant education resources and recommend the classified education resources to the learners' classifications which are suit for them to learn. The things mentioned above are the real meaning of achieving the individuality self-guide.

(2) The learners' process data in the process of learning resources will be recorded. According to these operational information we can analyze the learners' learning beginning and end time, duration time, learning resources category, contents and so on. According to the learners' operating data, we can analyze and modify the learners' recommended resources rules. That is to say, we can modify the similarity information between the learners and resources. Under the common guidance of the design standard, design concept, software design principle and training design principle, we can design the remote operations education training service platform with individuality self-guide.

\section{Conclusion}

With the popularity of information network and computer, making use of the network to inquire the information and date is used by more and more students. The goal is to achieve the real-time, fast and convenient educational administration management. The educational administration management system of TV University is the brand new management mode which breaks through the limit of space and time. A set of remote educational administration management system based on WEB is designed and realized in the paper. The main field of the future Internet application is the educational administration management system based on WEB. Due to the particularity of TV University work, a large number of requirements and development work need to be done before the development. Not only the analysis of management system processes needs to be 
arranged, but also the existing process and system needs to be optimized. The needs of remote education work from the system basically realize to be satisfied. And it promotes and pushes a more scientific and reasonable educational administration to a certain extent.

\section{References}

[1]Xu Yuanyuan. Applied Research on Open Courses in Cloud Computing Environment [D]. East China Normal University, 2013.

[2]Wang Xiaofan. The Influence on Interactive Behavior and Academic Performance in E-learning Training from Learning Style and Achievement Goal Orientation[D]. Tianjin normal university, 2013.

[3]Guo Suisui. Design and Practical Research of Exploratory Online Learning Activities[D]. Central China Normal University, 2014. 